
About IJMA [last updated July, $\left.1^{\text {st }}, 2021\right]$

$\checkmark$ International Journal of Medical Arts is the Official Journal of the Damietta Faculty of Medicine, AlAzhar University, Egypt

$\checkmark$ It is an International, Open Access, Double-blind, Peer-reviewed Journal

$\checkmark$ Published four times a year

$\checkmark$ The First Issue was published in July 2019

$\checkmark$ Published under the following license: Creative Commons Attribution-ShareAlike 4.0 International Public License (CC BY-SA 4.0). It had updated from the Creative Commons license [CC BY] in volume 2, Issue 4, October 2020 About IJMA

$\checkmark$ The Egyptian Knowledge Bank hosts the web site of IJMA

$\checkmark$ The Egyptian Knowledge Bank supports IJMA

$\checkmark$ IJMA follows the regulations of the International Committee of Medical Journal Editors

$\checkmark$ IJMA is indexed in the "Directory of Open Access Journals" [15 January 2021].

$\checkmark$ IJMA is indexed in JGate [29-6-2021]

$\checkmark$ IJMA is a member of the International Society of Managing and Technical Editors

$\checkmark$ Listed in "Index Copernicus", "Publons", "Academic resource index [ResearchBib]", "Electronics journal library", "Eurasian Scientific Journal Index", and "Citefactor"

$\checkmark$ IJMA introduced to the search engine [BASE] through DOAJ
Click image to reach the page

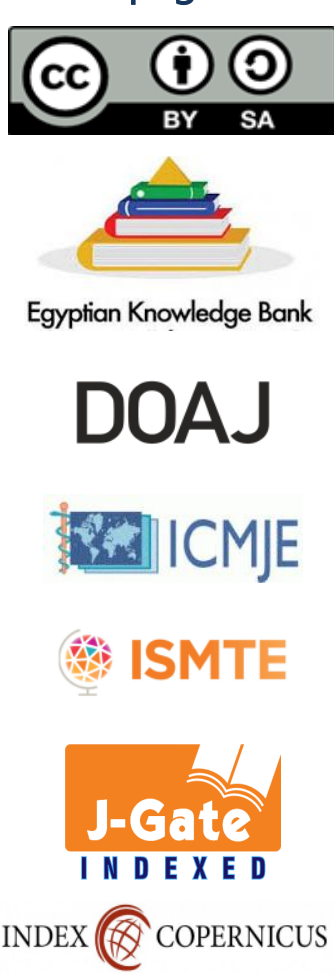

publons

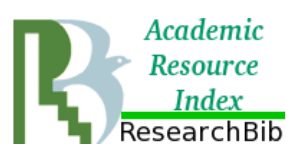

\section{EZ3 \\ .}

ESJII

CiteFactor

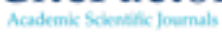

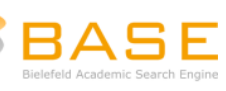




Available online at Journal Website
https://ijma.journals.ekb.eg/
Main subject [Anesthesia and Intensive Care] ${ }^{*}$

Original article

\title{
Radiofrequency Denervation of Genicular Nerves for Advanced Knee Osteoarthritis Pain: A retrospective Observational Study
}

\author{
Sandeep Khuba, Sanjay Kumar, Sujeet Gautam, Anil Agarwal, Chetna Shamshery, Keshav Kumar Garg, Rajput \\ Abhishek Kumar.
}

Sanjay Gandhi Postgraduate Institute of Medical Sciences, Lucknow, India.

Corresponding author: Sandeep Khuba.
Email: sandeepkhuba@gmail.com.

Submission date: March 22, 2021; Revision date: May 25, 2021; Acceptance date: May 25, 2021.

\section{ABSTRACT}

Background: Knee joint osteoarthritis is a degenerative disorder resulting in pain and disability. The treatment of knee osteoarthritis pain includes the use of oral analgesics, oral glucosamine and chondroitin sulfate, intra-articular steroid, and viscous supplementation, but with limited efficacy.

Aim of the work: This retrospective observational study aimed to evaluate the efficacy of radiofrequency thermocoagulation of genicular nerves for control of the pain of knee joint osteoarthritis.

Material and methods: This study included patients with knee pain of Kellgren Lawrence grade 3 and 4 osteoarthritis who underwent radiofrequency neurotomy of the knee joint from July 2015 to July 2018. The 68 joints of 60 patients were evaluated for knee pain VAS score [0-10 mm], oxford knee score [12-60] and development of any adverse effect at pre and post-procedure at $1,3,6$ and 12 months.

Results: The mean \pm SD values of Visual analog scale [VAS] [0-10] for knee joint pain were 7.93 $\pm 1.21,3.38 \pm 1.59,4.10 \pm 2.30$, $4.90 \pm 1.88$, and $5.80 \pm 1.71$ at pre-procedure and at $1,3,6$ and 12 months post-procedure. The mean \pm SD values for Oxford Knee Score [OKS] [12-60] were 40.87 $\pm 7.66,23.90 \pm 5.60,25.93 \pm 5.48,27.93 \pm 5.48$, and $31.43 \pm 5.62$ at pre-procedure and at 1, 3, 6 and 12 months post-procedure. One-way repeated measures of ANOVA test showed a significant decrease in VAS and OKS scores between pre and post-procedure at 1, 3, 6 and 12 months [p<0.001].

Conclusion: Radiofrequency thermocoagulation of genicular nerves provides significant pain relief and functional improvement in advanced knee joint osteoarthritis patients for a duration of one year.

Keywords: Radiofrequency Ablation; Local Anaesthetic Block; Knee Pain; Ultrasound Guided; Fluoroscope Guided.

This is an open-access article registered under the Creative Commons, ShareAlike 4.0 International license [CC BY-SA 4.0] [https://creativecommons.org/licenses/by-sa/4.0/legalcode. Osteoarthritis Pain: A retrospective Observational Study. IJMA 2021; 3 [3] July-September: 1576-1583 [DOI: 10.21608/IJMA.2021.68924.1286].

${ }^{*}$ Main subject and any subcategories have been classified according to the research topic. 


\section{INTRODUCTION}

Osteoarthritis is a degenerative disorder of synovial joints, resulting in pain and disability [1]. Weight-bearing joints are more susceptible to develop osteoarthritis. The knee is one of the joints commonly involved in osteoarthritis, particularly in the elderly population [2].

The pain perceived in OA knee is from non-cartilaginous structures like joint capsule, synovium, subchondral bone, ligaments, and periarticular muscles as cartilage itself is avascular and devoid of any sensory innervation [3]. The sensory innervation of knee joints consists of genicular branches from the femoral, tibial, and common peroneal, obturator and saphenous nerves ${ }^{[4]}$.

The sensory block of these nerves has been observed to provide pain relief in OA patients. Various other kinds of therapy which are prescribed for management of OA knee pain, includes the use of oral analgesics, oral glucosamine and chondroitin sulfate, intra-articular steroid, and viscous supplementation, but with limited efficacy ${ }^{[5]}$.

The duration of sensory block of a nerve could be enhanced by thermal ablation. The radiofrequency thermocoagulation is a method of thermal ablation which involves application of electromagnetic field at high frequency to neural tissues. This leads to increase in tissue temperature and resulting in thermos-coagulation [6].

Recently, radiofrequency thermocoagulation of knee genicular nerves has been proposed to control the pain of moderate to severe knee joint osteoarthritis for up to 6 months.

\section{AIM OF THE WORK}

In this study, we intend to find the efficacy of radiofrequency thermocoagulation of genicular nerves for control of the pain of advanced knee joint osteoarthritis for a duration of one year.

\section{MATERIALS AND METHODS}

\section{Study design and population:}

This retrospective cohort observational study is being conducted after the approval from institutional ethical committee with reference number PGI/BE/654/2020 dated 8 September 2020. The study included patients who underwent radiofrequency thermocoagulation of genicular nerve from January 2015 to December 2018 for knee osteoarthritis pain.

\section{Setting}

Pain clinic, Department of Anesthesiology

\section{Participants}

Inclusion criteria: The patients who underwent radiofrequency thermocoagulation of genicular nerves for advanced knee joint osteoarthritis pain [Figure 1]. The advanced knee osteoarthritis encompassed patients of Kellgren \& Lawrence grade ${ }^{[7]} 3 \& 4$ osteoarthritis [Table 1].

Table [1]: Kellgren-Lawrence classification of knee OA

\begin{tabular}{|c|l|}
\hline Grade & Description \\
\hline 0 & No radiologic features of osteoarthritis \\
\hline 1 & $\begin{array}{l}\text { Doubtful narrowing of joint space, possible osteophytic } \\
\text { lipping }\end{array}$ \\
\hline 2 & Possible narrowing of joint space, definite osteophytes \\
\hline 3 & $\begin{array}{l}\text { Definite narrowing of joint space, multiple osteophytes, } \\
\text { some subchondral sclerosis, possible bony deformity }\end{array}$ \\
\hline 4 & $\begin{array}{l}\text { Marked narrowing of joint space, large osteophytes, severe } \\
\text { subchondral sclerosis, definite bony deformity }\end{array}$ \\
\hline
\end{tabular}

Exclusion criteria: The patients with a history of knee surgery, trauma or any inflammatory systemic diseases were excluded.

\section{Source of data}

The hospital records of these patients were reviewed for demographic data, duration of symptoms, side, any adverse or side effects, pain VAS scores [0-10] ${ }^{[8]}$ and oxford knee scores [OKS] [12-60] [9] at time points of pre-procedure and post-procedure at 1, 3, 6 and 12 months.

\section{Sample size}

All the patients who underwent radiofrequency thermoscoagulation of genicular nerve from January 2015 to December 2018 for knee osteoarthritis pain and satisfying the inclusion criteria enrolled in the study.

\section{Primary outcome of interest}

\section{VAS score [pain] and Oxford knee scores}

VAS score for pain is calculated using a 0 to $10 \mathrm{~cm}$ horizontal line, where 0 corresponds to no pain and 10 to severe pain. The patient is asked to mark his or her current pain on this line. The point where the patient has marked on this line is measured and reported as the score. Oxford knee score is a self-administered questionnaire that consists of 12 questions relating to the pain and functional status of the patient. Each question is scored 1 to 5 with the 
severity of response increases with the score. The minimum score is 12 and the maximum score is 60 . The lesser is the score, and the better is the pain relief in the patient.

\section{Exposure}

All patients underwent radiofrequency thermoscoagulation of genicular nerves after successful diagnostic genicular nerve block. The successful diagnostic genicular nerve block was defined as more than $50 \%$ pain relief for at least 24 hours with $2 \mathrm{ml}$ of $1 \%$ lidocaine. The diagnostic block of superomedial, superolateral and inferomedial genicular nerves was done under ultrasound guidance and radiofrequency thermocoagulation under a fluoroscope.

\section{Ethics}

The procedures were performed after obtaining written informed consent for the procedure and possible publication of the data.

\section{Diagnostic genicular nerve block procedure.}

The patient was placed supine on the operating table [OT] with the knee in slight flexion. The periarticular area of the knee was prepared aseptically with povidone-iodine and draped. The high frequency [6-13 Mhz] linear probe of the ultrasound machine [M-Turbo, Fujifilm Sonosite USA] was placed longitudinally at the junction of the shaft and epicondyle of femur medially and laterally for superomedial [Figure 2] and superolateral [Figure 3] genicular nerve, respectively. The inferomedial genicular nerve was blocked at the junction of the shaft and medial condyle of the tibia. [Figure 4]. These genicular nerves are accompanied by their respective genicular arteries. Once the genicular artery is visualized under ultrasound imaging, a 26 G, 11/2-inch needle [Romsons, India] is introduced in an "out of plane approach" and $2 \mathrm{ml}$ of $1 \%$ lidocaine is deposited around the artery to block the nerve. [Figure 5].

\section{Radiofrequency denervation of genicular nerve procedure.}

The patients were placed supine on the OT table with the knee in 30 degrees of flexion. After aseptic preparation of the part, the fluoroscope was used in PA view with a craniocaudal tilt to guide the entry point of the needle. A 22 $\mathrm{G}, 10 \mathrm{~cm}$ radiofrequency needle with $1 \mathrm{~cm}$ active tip [Cosman cannula CC, Cosman Medical Inc, Burlington, MA, USA] and the radiofrequency generator [G4-257, Cosman Medical Inc, Burlington, MA, USA] were used for the radiofrequency thermocoagulation. The skin and subcutaneous tissue infiltrated with $2-3 \mathrm{ml}$ of lignocaine $1 \%$ at the entry point of the needle. The needle was inserted at the junction of the shaft and epicondyle of femur medially and laterally for the superomedial and superolateral genicular nerve, respectively [Figure 6, figure 7].

The junction of the shaft and medial condyle of the tibia was targeted for inferomedial genicular nerve. [Figure 8] The depth of the needle was confirmed in lateral view. The target point for the tip of the needle in the lateral view was in the middle of the shaft of the femur and tibia. [Figure 9 , 10]. After reaching the target point, sensory stimulation at $50 \mathrm{~Hz}$ and motor stimulation at $2 \mathrm{~Hz}$ was done. The patient was asked to report any sensation of pain, paresthesia, or formication in or around the knee joint. If patients reported these sensations below $0.5 \mathrm{~V}$, then the location of the genicular nerve was confirmed. Thereafter, the patient was asked to report any contraction or fasciculations of the muscles on motor stimulation up to $2 \mathrm{~V}$. If motor stimulation was negative, only then thermocoagulation of the nerve was done. The sensory and motor stimulation was done to exactly localize the genicular nerve and to prevent the denervation of any motor nerve. After that, $2 \mathrm{ml}$ of $2 \%$ lidocaine was given to anaesthetize the nerve. The thermocoagulation was done at a temperature of 80 degrees for 90 seconds. All the 3 genicular nerves were thermo-coagulated similarly. Thereafter, $2 \mathrm{mg}$ of dexamethasone was given through the same needle to prevent neuritis of the nerve. After that, the patients were shifted to a recovery room. The patients were observed and was discharged after 2 hours. All patients were advised a short course of oral aceclofenac $100 \mathrm{mg}$ twice a day for 3 days and after that oral tramadol/paracetamol combination [37.5 mg/325 mg] if they experience pain with VAS more than 3 . The patients were also advised to continue kneestrengthening exercises.

\section{Statistical analysis}

The demographic data are presented as Means $\pm S D$ for numerical data and as frequency and number for categorical data. The VAS scores and oxford knee scores are presented as Means $\pm S D$. The pre-procedure and post-procedure VAS and oxford knee scores at 1, 3,6 and 12 months are compared with one-way repeated measures of the ANOVA test. A $p<0.05$ is considered significant. The data were analyzed with SPSS version 13.0 [SPSS Inc., Chicago, III., USA].

\section{RESULTS}

A total of 60 patients were included in the study. Of 60 patients, 40 were male. The mean age and weight of the patients were $63.85 \pm 8.17$ years and $67.40 \pm 9.20 \mathrm{~kg}$ respectively. The mean duration of the symptoms was $10.15 \pm 7.51$ years. The descriptive data are presented in 
[Table 2]. A total of 150 patients with knee joint osteoarthritis who failed conservative therapy for at least 3 months from January 2015 to December 2018 were screened for genicular nerve block [Figure 1]. Of the 150 patients, 92 with Kellgren \& Lawrence grade 3 \& 4 knee joints osteoarthritis underwent diagnostic genicular nerve block. Of the 92,65 patients reported more than $50 \%$ pain relief for more than 24 hours after the diagnostic block, who later underwent radiofrequency thermocoagulation of genicular nerves. Five patients were excluded from data analysis because of exclusion criteria. Two patients had a history of knee arthroplasty, one patient had meniscal injury and two patients were having rheumatoid arthritis. The demographic and clinical data of 68 joints of 60 patients treated with radiofrequency thermocoagulation of genicular nerves were finally included for data analysis. The VAS scores [Means \pm SD] and OKS scores at different time points are presented in [Table 3]. There is a significant association between VAS scores, OKS scores and time points. Both the VAS scores and OKS scores showed a significant positive interaction between pre-procedure and post-procedure time points. [Table 3]. None of the patients in the study reported the development of any serious adverse effects or complication like neuropathic pain, joint swelling, Charcot joint or infection. Seven patients reported increased pain at the needle insertion site for 2-3 days, which was controlled after taking oral aceclofenac $100 \mathrm{mg}$ twice a day.

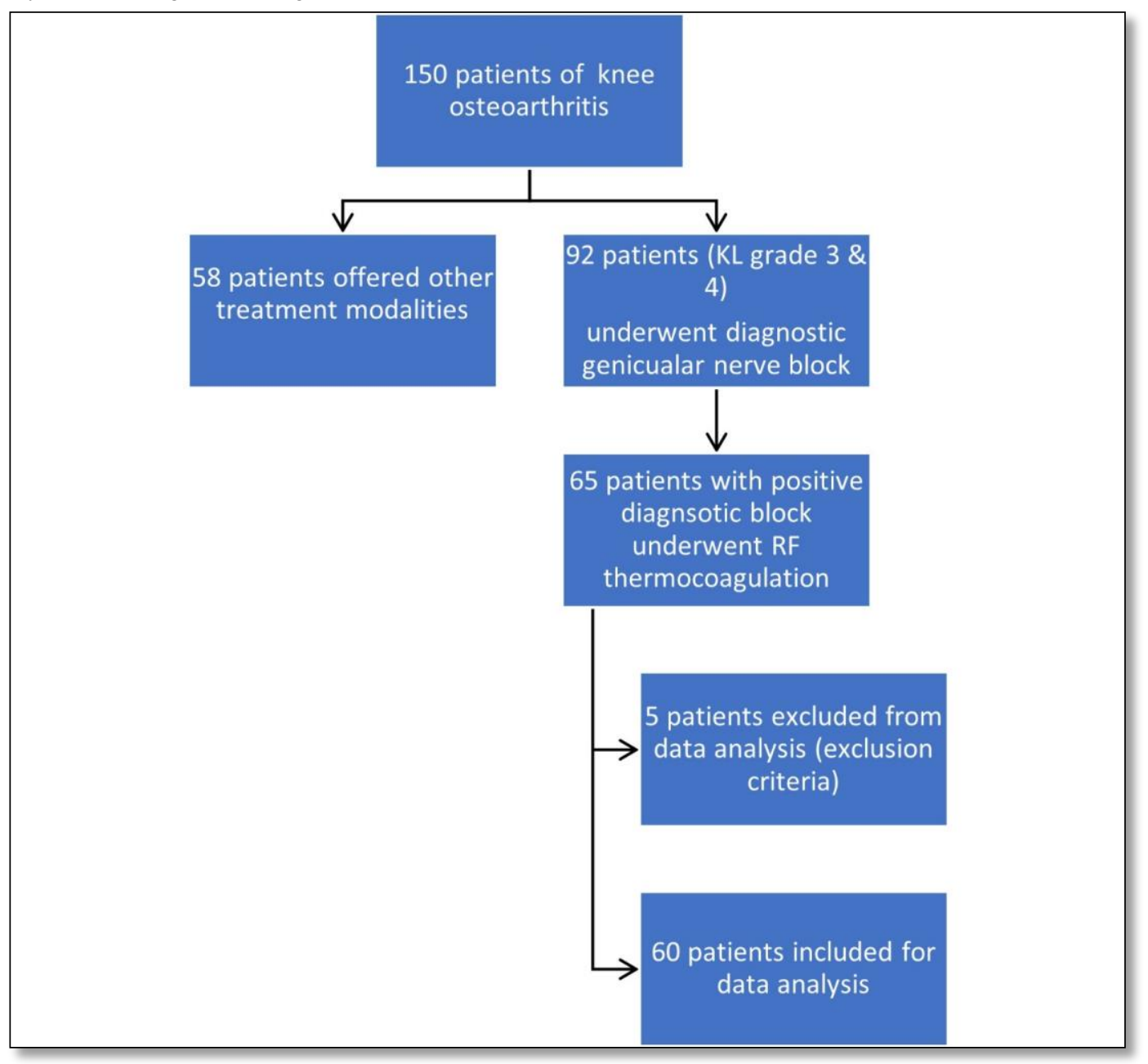

Figure [1]: Flowchart of inclusion of patients in the study.

Table [2]: Distribution of demographic data [ $\mathrm{n}=60]$

\begin{tabular}{|l|c|}
\hline Male: Female [n] & $40: 20$ \\
\hline Age [years] [Mean \pm SD] & $63.85 \pm 8.17$ \\
\hline Weight [Kilogram] [Mean $\pm S D]$ & $67.40 \pm 9.20$ \\
\hline Duration of symptoms [years] & Means $\pm S D: 10.15 \pm 7.51 ;$ Median [IQR]:8 [5,11]; Range:3-36 \\
\hline KL grading III/IV [number of joints] & $43 / 25$ \\
\hline Side [Right/Left/bilateral] [n] & $23 / 29 / 8$ \\
\hline
\end{tabular}




\begin{tabular}{|c|c|c|}
\hline \multicolumn{3}{|c|}{ Table [3]: Distribution of VAS and OKS scores in study patients [n=60] } \\
\hline & $\begin{array}{l}\text { VAS scores } \\
[M e a n \pm S D]]\end{array}$ & $\begin{array}{l}\text { OKS score } \\
{[M e a n \pm S D]}\end{array}$ \\
\hline Pre procedure & $7.93 \pm 1.21$ & $40.87 \pm 7.66$ \\
\hline Post procedure 1 months & $3.78 \pm 1.59$ & $23.90 \pm 5.60$ \\
\hline Post procedure 3 months & $4.10 \pm 2.30$ & $25.93 \pm 5.48$ \\
\hline Post procedure 6 months & $4.90 \pm 1.88$ & $27.93 \pm 5.48$ \\
\hline Post procedure 12 months & $5.80 \pm 1.71$ & $31.43 \pm 5.62$ \\
\hline One-way Repeated measures of ANOVA test [ $p$ value] & $<0.001$ & $<0.001$ \\
\hline $\begin{array}{l}\text { Pairwise comparison form pre procedure to } 1 \text { month, } 3 \text { months, } 6 \text { months and } 12 \text { months [p } \\
\text { value }<0 \text { ] }\end{array}$ & All time points & All time points \\
\hline
\end{tabular}

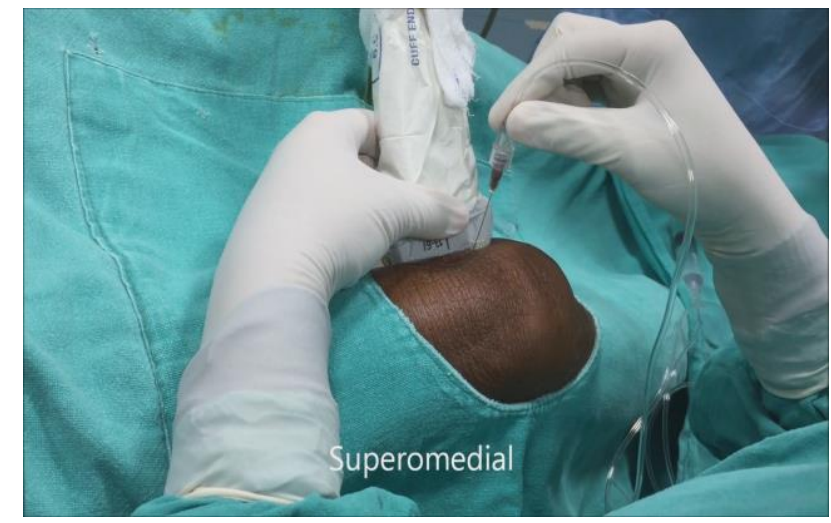

Figure [2]: Superomedial genicular nerve block.

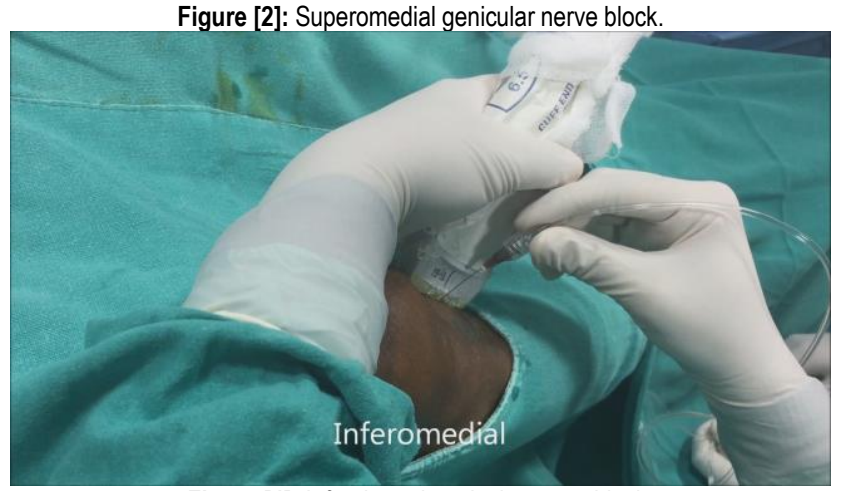

Figure [4]: Inferolateral genicular nerve block.

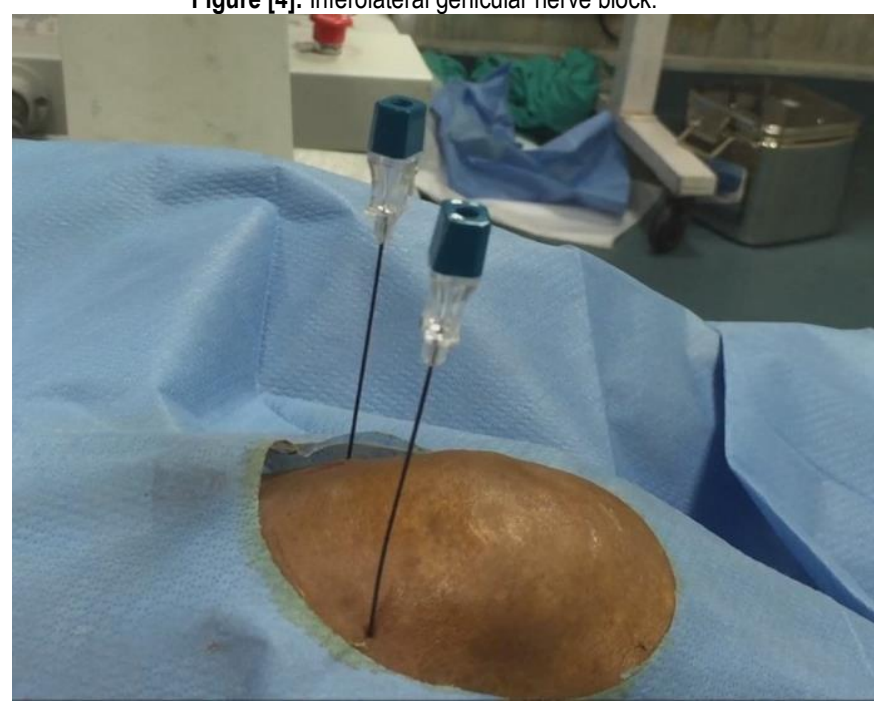

Figure [6]: Radiofrequency needles at superomedial and superolateral genicular nerve.

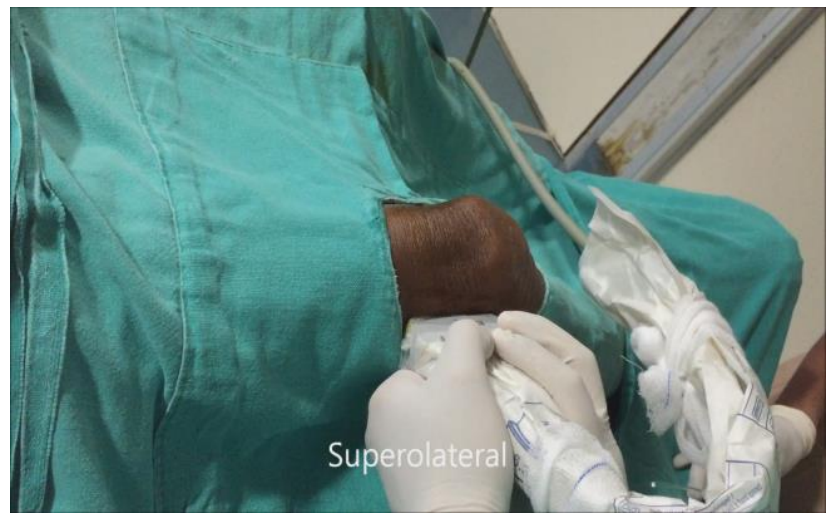

Figure[3]: Superolateral genicular nerve block.

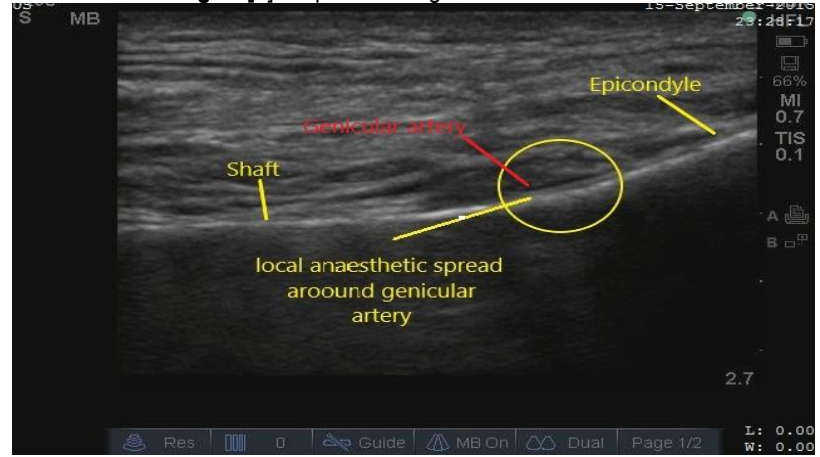

Figure [5]: Local anesthetic spread around genicular artery.

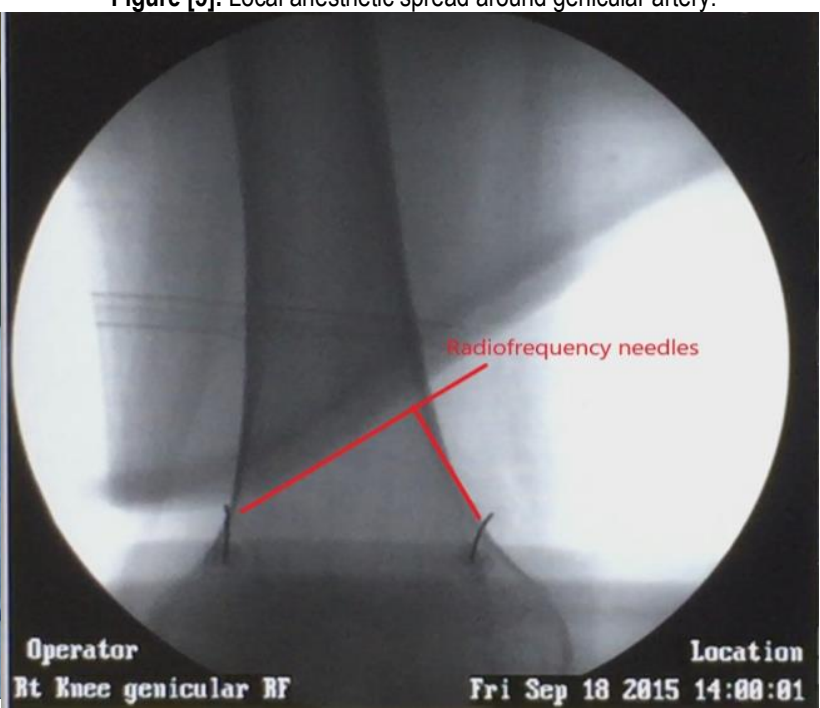

Figure [7]: AP view, Radiofrequency needles at superomedial and superolateral genicular nerve. 


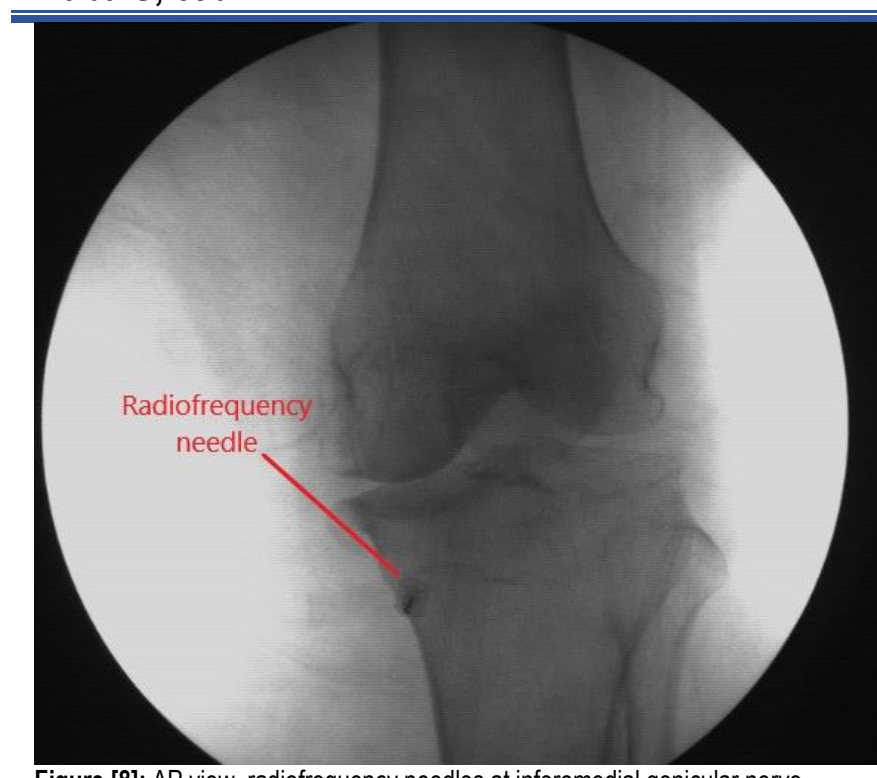

Figure [8]: AP view, radiofrequency needles at inferomedial genicular nerve.

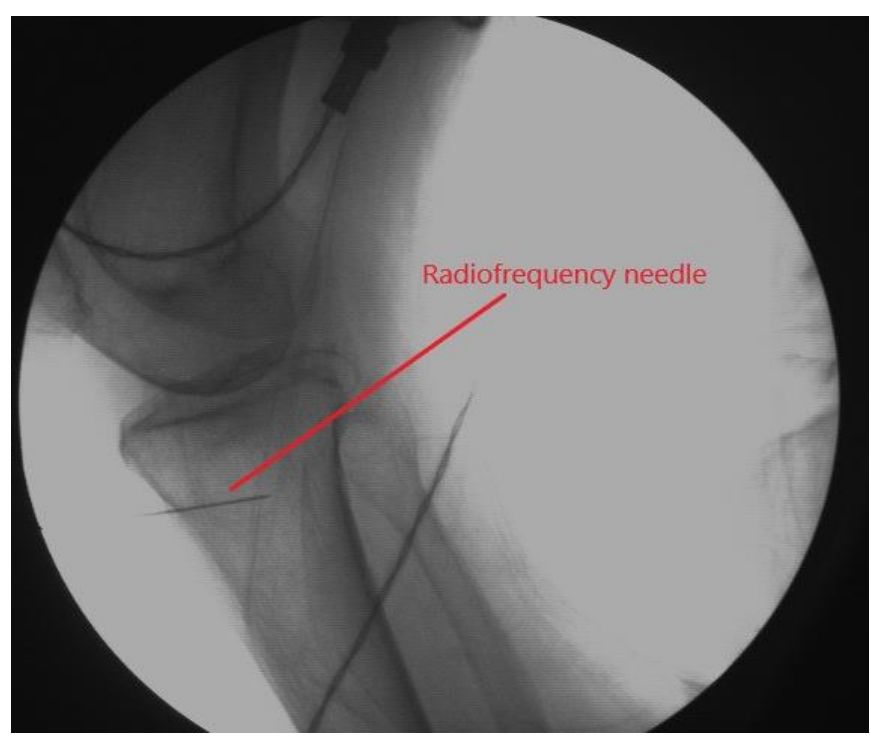

Figure [10]: Lateral view, Radiofrequency needles at inferomedial genicular nerve.

\section{DISCUSSION}

The present study shows that there is significant relief in pain and functional improvement in patients with advanced knee joint osteoarthritis [Kellgren \& Lawrence grade 3 \& 4] after undergoing radiofrequency thermocoagulation of genicular nerves for a duration of 1 year [Table 3]. Choi et al. first demonstrated the efficacy of radiofrequency denervation of genicular nerves in knee osteoarthritis [KL grade 2-4] patients. They reported improvement in pain relief and function in patients with knee joint osteoarthritis for up to 12 weeks ${ }^{[10]}$.

This study has reported similar findings in patients with advanced osteoarthritis [KL grade 3-4] patients with follow up of 1 year duration. Various studies in different study

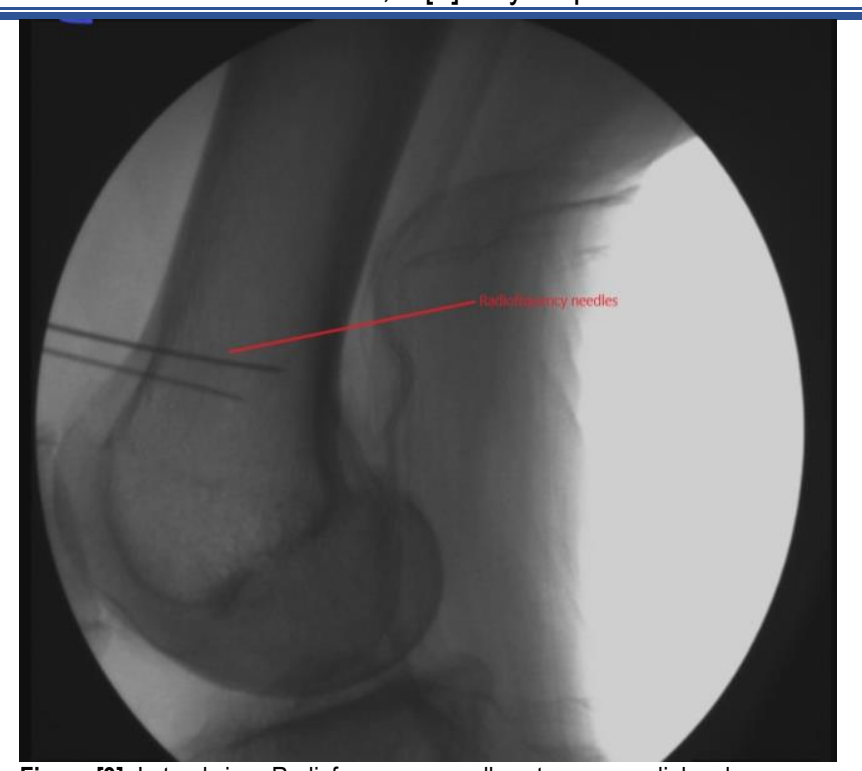

Figure [9]: Lateral view, Radiofrequency needles at superomedial and superolateral genicular designs have demonstrated the efficacy of genicular nerve block for 3 to 6 months in the improvement of pain and functional status of the patients ${ }^{[10-14]}$.

The genicular nerve block has been done with local anesthetics with or without steroids [11], alcohol [12], and pulsed radiofrequency ${ }^{[13]}$ in different studies. These studies agreed upon the fact that genicular nerve treatment is a safe, effective, and viable treatment option for knee joint osteoarthritis pain. This is particularly relevant for elderly patients who have failed conservative management and are poor surgical candidates.

In this study, we have demonstrated the efficacy of genicular nerve ablation for up to 1 year as compared to previous studies, which showed efficacy up to 3 to 6 months. 
This might be because of the careful selection of the patients for nerve ablation. Only those patients with knee osteoarthritis [KL grade 3 and 4] were selected for nerve ablation who demonstrated more than $50 \%$ pain relief for more than 24 hours on the diagnostic block. The patients were also advised to continue their physical therapy to supplement the genicular nerve block.

All the patients under study received $2 \mathrm{mg}$ of perineural dexamethasone at each genicular nerve site after the thermocoagulation to prevent development of any neuritis later. The perineural dexamethasone has been shown to prolong the analgesic effect of local anesthetic [15].

The mechanism of action involves blockage of nociceptive $\mathrm{c}$ fibers by direct membrane action of corticosteroids rather than anti-inflammatory effects ${ }^{[16]}$.

The addition of corticosteroids with local anesthetic has been investigated for the genicular nerve block. One study has reported the benefit of steroid for up to two months [11] and another study demonstrated benefit to 6 months [17].

In our study, it may be likely that dexamethasone has contributed to pain relief but benefit lasting up to one year is unlikely because of it.

The nerve supply of knee joints consists of articular branches of the femoral, tibial, and common peroneal, obturator and saphenous nerves ${ }^{[4]}$.

Blocking the sensory supply of a chronic painful joint leads to improvement in its pain relief and function. Of all the genicular nerves, this study targeted superomedial, superolateral and inferomedial genicular nerves as these nerves can be blocked by using anatomic landmarks ${ }^{[10]}$.

The anatomic dissections have demonstrated that the 3 genicular nerves i.e., superomedial, superolateral and inferolateral genicular nerves have a consistent relationship with the respective genicular arteries. An ultrasound imaging can identify vascular structures, so it was used for genicular nerve block. Under ultrasound guidance, a local anesthetic can be deposited around the genicular arteries to block the nerves. In this study, we have used ultrasound imaging to do the diagnostic genicular nerve block because of the same reason.

Kim et al. ${ }^{[18]}$ compared the efficacy of ultrasound and fluoroscope for local anesthetic block of genicular nerves in chronic knee osteoarthritis patients. They found both the modalities equally efficacious for pain relief, but they advocated ultrasound as a modality of choice because it is devoid of radiation exposure.
This study included patients for radiofrequency thermocoagulation of genicular nerves who had more than $50 \%$ pain relief for at least 24 hours the following diagnostic local anesthetic block. Local anesthetic drugs lead to temporary interruption of nociception, sensory or motor signals depending upon the dose of local anesthetic. The analgesic effect of the local anesthetic block in chronic painful conditions usually outlives the duration of action of the local anesthetic. It may be because the local anesthetic leads to temporary interruption of nociceptive input to the dorsal root ganglion, which helps in decreasing central sensitization. Once the action of local anesthetic ends, it may take a noxious input considerable time to develop central sensitization again [19]. This may be the reason why the patients included in this study had pain relief for more than 24 hours after the diagnostic block.

The fluoroscope was used for radiofrequency thermocoagulation of the genicular nerves. This is because to create adequate thermal lesioning of a nerve, the radiofrequency needle should be parallel to the nerve. This is not possible with ultrasound imaging as it involves placing the needle perpendicular to the nerve. The application of radiofrequency current to neural tissue creates an electromagnetic field around it, which leads to oscillation of molecules at high frequency. This oscillation of molecules at high frequency leads to the generation of heat energy, ultimately leading to thermal ablation. ${ }^{[6]}$ The size of the thermal lesion can be controlled by manipulating the probe size, active tip length, temperature setting and duration. [20]

\section{Limitations of the study:}

Although we have studied the radiofrequency thermocoagulation of genicular nerves for up to one year in advanced knee osteoarthritis pain, but it is a retrospective observational study and without any comparison group. So, it may be advisable in future to study this modality for knee osteoarthritis pain in more robust study designs like randomized controlled trials.

\section{Conclusion:}

The radiofrequency nerve ablation of genicular nerves after a positive diagnostic block is safe, effective, and viable treatment options for the pain of advanced knee joint osteoarthritis for a duration of one year.

Financial and Non-financial Relationships and Activities of Interest

None 


\section{REFERENCES}

1. Rice $D$, McNair $P$, Huysmans $E$, Letzen J, Finan P. Best Evidence Rehabilitation for Chronic Pain Part 5: Osteoarthritis. J Clin Med. 2019 Oct 24; 8[11]:1769. [DOI: 10.3390/ jcm8111769].

2. Driban JB, Harkey MS, Barbe MF, Ward RJ, MacKay JW, Davis JE, Lu B, Price LL, Eaton CB, Lo GH, McAlindon TE. Risk factors and the natural history of accelerated knee osteoarthritis: a narrative review. BMC Musculoskelet Disord. 2020 May 29; 21[1]:332. [DOI: 10.1186/s12891-020-03367-2].

3. Mora JC, Przkora R, Cruz-Almeida Y. Knee osteoarthritis: pathophysiology and current treatment modalities. J Pain Res. 2018 Oct 5; 11:2189-2196. [DOI: 10.2147/JPR.S154002].

4. Hirasawa Y, Okajima S, Ohta M, Tokioka T. Nerve distribution to the human knee joint: anatomical and immune-histochemical study. Int Orthop. 2000; 24 [1]:1-4. [DOI: 10.1007/ s002640050001]

5. Crawford DC, Miller LE, Block JE. Conservative management of symptomatic knee osteoarthritis: a flawed strategy? Orthop Rev [Pavia]. 2013 Feb 22; 5[1]: e2. [DOI: 10.4081/or. 2013.e2].

6. Rea W, Kapur S, Mutagi H. Radiofrequency therapies in chronic pain. Contin Educ Anaesth Crit Care Pain 2011; 11:35-38. [DOI: 10.1093/bjaceaccp/mkq057].

7. Kellgren Jh, Lawrence Js. Radiological assessment of osteoarthrosis. Ann Rheum Dis. 1957 Dec; 16[4]:494-502. [DOI: 10.1136/ard.16.4.494].

8. Delgado DA, Lambert BS, Boutris N, McCulloch PC, Robbins $A B$, Moreno MR, Harris JD. Validation of Digital Visual Analog Scale Pain Scoring With a Traditional Paper-based Visual Analog Scale in Adults. J Am Acad Orthop Surg Glob Res Rev. 2018 Mar 23; 2[3]:e088. [DOI: 10.5435/JAAOSGlobal-D17-00088].

9. Dawson J, Fitzpatrick R, Murray D, Carr A. Questionnaire on the perceptions of patients about total knee replacement. $J$ Bone Joint Surg Br. 1998 Jan;80[1]:63-9. [DOI: 10.1302/0301620x.80b1.7859. PMID: 9460955].

10. Choi WJ, Hwang SJ, Song JG, Leem JG, Kang YU, Park PH, Shin JW. Radiofrequency treatment relieves chronic knee osteoarthritis pain: a double-blind randomized controlled trial. Pain. 2011 Mar;152[3]:481-487. [DOI: 10.1016/j.pain.2010. 09.029].

11. Kim DH, Choi SS, Yoon SH, Lee SH, Seo DK, Lee IG, Choi WJ, Shin JW. Ultrasound-Guided Genicular Nerve Block for Knee Osteoarthritis: A Double-Blind, Randomized Controlled Trial of Local Anesthetic Alone or in Combination with Corticosteroid. Pain Physician. 2018 Jan; 21[1]:41-52. [PMID: 29357330].
12. Ahmed A, Arora D. Ultrasound-Guided Neurolysis of Six Genicular Nerves for Intractable Pain from Knee Osteoarthritis: A Case Series. Pain Pract. 2019 Jan;19[1]:1626. [DOI: 10.1111/papr.12710].

13. Kesikburun S, Yaşar E, Uran A, Adigüzel E, Yilmaz B. Ultrasound-Guided Genicular Nerve Pulsed Radiofrequency Treatment For Painful Knee Osteoarthritis: A Preliminary Report. Pain Physician. 2016 Jul;19[5]: E751-9. [PMID: 27389118].

14. Jadon $A$, Jain $P$, Motaka $M$, Swarupa $C P$, Amir $M$. Comparative evaluation of monopolar and bipolar radiofrequency ablation of genicular nerves in chronic knee pain due to osteoarthritis. Indian J Anaesth. 2018 Nov;62[11]:876-880. [DOI: 10.4103/ija.IJA_528_18].

15. Albrecht E, Kern C, Kirkham KR. A systematic review and meta-analysis of perineural dexamethasone for peripheral nerve blocks. Anaesthesia. 2015 Jan;70[1]:71-83. [DOI: 10.1111/anae.12823]

16. Johansson A, Hao J, Sjölund B. Local corticosteroid application blocks transmission in normal nociceptive C-fibres. Acta Anaesthesiol Scand. 1990 Jul;34[5]:335-8. [DOI: 10.1111/j.1399-6576. 1990.tb03097.x].

17. Qudsi-Sinclair S, Borrás-Rubio E, Abellan-Guillén JF, Padilla Del Rey ML, Ruiz-Merino G. A Comparison of Genicular Nerve Treatment Using Either Radiofrequency or Analgesic Block with Corticosteroid for Pain after a Total Knee Arthroplasty: A Double-Blind, Randomized Clinical Study. Pain Pract. 2017 Jun;17[5]:578-588. [DOI: 10.1111/papr.12481].

18. Kim DH, Lee MS, Lee S, Yoon SH, Shin JW, Choi SS. A Prospective Randomized Comparison of the Efficacy of Ultrasound- vs Fluoroscopy-Guided Genicular Nerve Block for Chronic Knee Osteoarthritis. Pain Physician. 2019 Mar;22 [2]: 139-146. [PMID: 30921977].

19. Hogan QH, Abram SE. Neural blockade for diagnosis and prognosis. A review. Anesthesiology. 1997 Jan;86[1]:216-41. [DOI: 10.1097/00000542-199701000-00026].

20. Cosman ER Jr, Dolensky JR, Hoffman RA. Factors that affect radiofrequency heat lesion size. Pain Med. 2014 Dec; 15 [12]: 2020-36. [DOI: 10.1111/pme.12566]. 

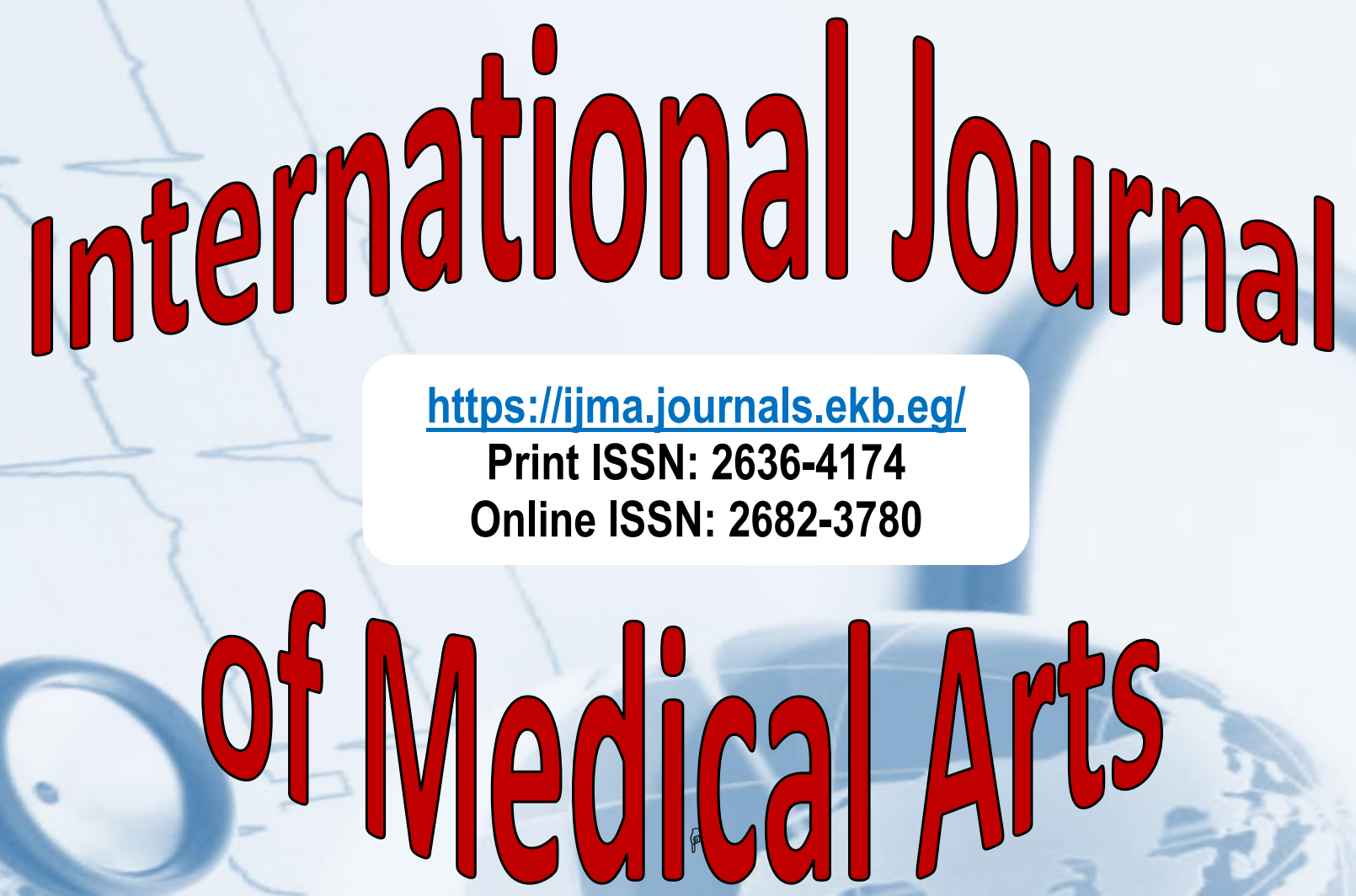